\title{
KAJIAN TINGKAT PEMAHAMAN MAHASISWA AKUNTANSI TERHADAP SISTEM PENGADAIAN SYARIAH
}

\author{
Rosmiati $^{1 *}$, Puteri Ayu Pratiwi ${ }^{2}$ \\ ${ }^{1,2)}$ Jurusan Akuntansi Politeknik Negeri Kupang \\ *Email : rosmiati99@gmail.com
}

\begin{abstract}
Abstrak
Gadai menurut istilah syariah adalah menahan sesuatu disebabkan adanya hak yang memungkinkan hak itu bisa dipenuhi dari sesuatu tersebut.Maksudnya menjadikan al-Aini (barang, harta yang barangnya berwujud konkrit, kebalikan dari ad-Dain atau utang) yang memiliki nilai menurut pandangan syara' sebagai watsiqah (pengukuhan, jaminan) utang, sekiranya barang itu memungkinkan untuk digunakan membayar seluruh atau sebagian utang yang ada.Tujuan dari penelitian ini adalah untuk mengetahui pemahaman mahasiswa akuntansi tentang pegadaian syariah.

Metode penelitian ini adalah survey dengan pendekatan analisis kuantitatif. Teknik pengambilan sampel yaitu Simple Random Sampling, pengumpulan data menggunakan kuesioner. Alat Analisis data yang digunakan dalam penelitian ini adalah regresi linier berganda dengan uji validitas, uji reliabilitas, uji-F. Semua analisis diatas dihitung menggunakan program SPSS 16.

Hasil pengujian dinyatakan bahwa variabel mata kuliah Bank dan Lembaga Keuangan berpengaruh signifikan terhadap pemahaman sistem pegadaian syariah.
\end{abstract}

Keywords : Gadai, pemahaman, sistem gadai syariah, pengadaian syariah.

\section{PENDAHULUAN}

Sampai saat ini masih ada kesan dalam masyarakat, apabila seseorang pergi ke pegadaian untuk menjamin sejumlah uang dengan cara menggadaikan barang, hal ini sebahagian orang menganggap aib dan seolah-olah kehidupan orang tersebut sudah sangat menderita, karena itu banyak diantara masyarakat yang merasa malu menggunakan fasilitas pengadaian. Hal yang berbeda apabila kita pergi ke sebuah Bank, disana akan terlihat lebih prestisius, meskipun dalam prosesnya memerlukan waktu yang relatif lebih lama dengan persyaratan yang cukup rumit. Bersamaan dengan perkembangansebuah Bankdan Asuransi yang berdasarkan prinsip syariah di Indonesia, maka hal tersebut yang mendasari lahirnya pegadaian syariah (Rahn) yang lebih dikenal sebagai produk yang ditawarkan oleh Bank Syariah.

Fungsi Bank dan Lembaga Keuangan sebagai menyalurkan dana kepada masyarakat dalam bentuk penjaminan barang guna mendapatkan pembiayaan. Pada saat ini pegadaian syariah sudah terbentuk sebagai sebuah lembaga keuangan yang diawasi Otoritas Jasa Keuangan (OJK). Ide pembentukan pegadaian syariah selain karena tuntutan idealisme juga dikarenakan keberhasilan LembagaBank dan Asuransi Syariah, Pasar Modal Syariah yang bersifat universal, dapat dimanfaatkan oleh siapapun tanpa 
melihat latar belakang suku, agama dan ras tertentu.

Lembaga pegadaian syariah adalah memberikan pinjaman kepada masyarakat yang membutuhkan. Pemberian pinjaman initidak terbatas untuk kalangan atau kelompok masyarakat tertentu, namundi Indonesia pemanfaat lembaga keuangan ini masih didominasi oleh kalangan menengah ke atas, dan masih sedikit menjangkau kalangan menengah ke bawah. Salah satu bentuk muamalah yang diperbolehkan oleh Rasulullah SAW adalah gadai (Rachmad Saleh, 2016). Praktik gadai ini sudah ada sejak zaman Rasulullah SAW, yang mana Rasulullah SAW sendiri yang melakukan praktikini sebagaimana sabdanya:" Nabi SAW pernah menggadaikan baju besinya kepada orang Yahudi untuk ditukar dengan gandum. Lalu orang Yahudi berkata: "Sungguh Muhammad ingin membawa lari hartaku", Rasulullah SAW, kemudian menjawab: "Bohong! Sesungguhnya Aku orang yang jujurdi atas bumi ini dan di langit. Jikakamu berikan amanat kepadaku, pastilah Aku tunaikan. Pergilah kalian dengan baju besiku menemuinya."(Sabiq, 1996). Gadai juga merupakan bagian dari transaksi yang diperbolehkan dalam kondisi di tengah perjalanan, seperti tercantum dalam QS. Al-Baqarah: 283. Namun gadai juga diperbolehkan dalam keadaan tidak berpergian sesuai dengan hadist yang diriwayatkan oleh Aisyah R.A yang menceritakan bahwa Rasulullah SAW membeli makanan dari seorang Yahudi yang dibayarkan secara tunda dan beliau menggadaikan alat perangnya (At-Tariqi, 2004).

Berdasarkan hasil penelitian Nasution (2016) menyatakan bahwa sistem operasional yang ada di Pegadaian Syariah dengan Pegadaian Konvensional walaupun ada kemiripan, akan tetapi terdapat juga perbedaan. Perbedaan yang mendasar yang sifatnya fundamental yaitu Akad atau transaksi yang digunakan Pegadaian
Konvensional berdasarkan Perjanjian Perdata, sedangkan pada Pegadaian Syariah didasarkan pada fiqh Muamalah yang berlandaskan Al Qur'an dan Hadist. Barang yang digunakan dalam gadai Pegadaian Konvensional harus berupa emas atau barang yang bergerak, berbeda halnya dengan Pegadaian Syariah dimana berdasarkan fiqh Muamalah untuk akad rahn, barang yang digadaikan tidak dibatasi pada emas atau barang bergerak saja namun mencakup segala jenis barang yang berharga atau bernilai.

Menurut Al hafizh (2013) menyatakan bahwa pemahaman merupakan suatu proses berpikir dan belajar. Dikatakan demikian karena, untuk menuju ke arah pemahaman perlu diikuti dengan belajar dan berpikir. Pemahaman merupakan proses, perbuatan dan cara memahami. Dalam Taksonomi Bloom (1985), menyatakan bahwa pemahaman adalah kemampuan untuk menangkap makna dan arti tentang hal yang dipelajari. Kemampuan ini setingkat lebih tinggi daripada pengetahuan. Pengetahuan menjadi prasyarat bagi tingkatan selanjutnya, dimana pada jenjang ini seseorang menjawab pertanyaan berdasarkan hafalan sedangkan pada tingkatan pemahaman seseorang menjawab pertanyaan dengan kata-katanya sendiri dan dengan memberikan contoh prinsip maupun konsep. Permasalahan terjadi bahwa seiring perkembangan Pegadaian Syariah di Indonesia yakni kecenderungan mahasiswa belum memahami pegadaian syariah. Tujuan penelitian ini untuk mendapatkan gambaran pemahaman mahasiswa akuntansi tentang pengadaian syariah. Berdasarkan uraian diatas maka peneliti mengadakan penelitian mengenai "Kajian Tingkat Pemahaman Mahasiswa Akuntansi Terhadap Sistem Pegadaian Syariah Pada Mahasiswa Akuntansi Politeknik Negeri Kupang." 


\section{TINJAUAN PUSTAKA}

\section{Pegadaian Syariah}

Gadai (rahn) secara bahasaartinya bisa ats-Tsubuut dan ad-Dawaam (tetap dan kekal), dikatakan, maaun raahinun (air yang diam, menggenang tidak mengalir), atau ada kalanya berarti al-Habsu danLuzuum (menahan). Allah SWTberfirman: "Tiap-tiap diri tertahan (bertanggungjawab) oleh apa yang telah diperbuatnya." (Al-Muddatsir: 38). Sedangkan definisi ar-rahn menurut istilah syara' adalah, menahan sesuatu disebabkan adanya hak yang memungkinkan hak itu bisa dipenuhi dari sesuatu tersebut. Maksudnya menjadikan al-Aini (barang, harta yang barangnya berwujud konkrit, kebalikan dari ad-Dain atau utang) yang memiliki nilai menurut pandangan syara' sebagai watsiqah (pengukuhan, jaminan) utang, sekiranya barang itu memungkinkan untuk digunakan membayar seluruh atau sebagian utangyang ada. Adapun sesuatu yang dijadikan watsiqah (jaminan) haruslah sesuatu yang memiliki nilai, maka itu untuk mengecualikan al-Ain (barang) yang najis dan barang yang terkena najis yang tidak mungkin untuk dihilangkan, karena dua bentuk al-Ainini (yang najis dan terkena najis yang tidak mungkin dihilangkan) tidak bisa digunakan sebagai watsiqah (jaminan) utang (Rachmad Saleh, 2016).

\section{Pemahaman}

$\begin{array}{crr}\text { Pemahaman } & \text { berarti proses } \\ \text { perbuatan cara memahami atau }\end{array}$ memahamkan. Pemahaman merupakan proses berpikir dan belajar. Dikatakan demikian karena untuk menuju ke arah pemahaman perlu diikuti dengan belajar dan berpikir. Pemahaman merupakan proses, perbuatan dan cara memahami. Pemahaman adalah tingkatan kemampuan yang mengharapkan seseorang mampu memahami arti atau konsep, situasi serta fakta yang diketahuinya. Dalam hal ini ia tidak hanya hapal secara verbalitas, tetapi memahami konsep dari masalah atau fakta yang ditanyakan, maka operasionalnya dapat membedakan, mengubah, mempersiapkan, menyajikan, mengatur, menginterpretasikan, menjelaskan, mendemonstrasikan, memberi contoh, memperkirakan, menentukan, dan mengambil keputusan. (Purwanto, 1997). Sedangkan Pemahaman adalah mencakup kemampuan untuk menangkap makna dan arti dari bahan yang dipelajari. Adanya kemampuan ini dinyatakan dalam menguraikan isi pokok dari suatu bacaan, mengubah data yang disajikan dalam bentuk tertentu ke bentuk lain, seperti rumus matematika ke dalam bentuk katakata, membuat perkiraan tentang kecenderungan yang nampak dalam data tertentu, seperti dalam grafik (Winkel, 1996:246).

\section{Konsep Emas}

Fatwa Dewan Syariah Nasional Nomor: 26/DSN-MUI/III/2002 yang ditetapkan pada tanggal 28 Maret $2002 \mathrm{M}$, tentang Rahn Emas memutuskan bahwa: 1) Rahn Emas dibolehkan berdasarkan prinsip rahn (lihat Fatwa DSN Nomor: 25/DSNMUI/ III/2002 tentang Rahn), 2) Ongkos dan biaya penyimpanan barang (Marhun) ditanggung oleh penggadai (rahin), 3) Ongkos sebagaimana dimaksudayat 2 besarnya didasarkan pada pengeluaran yang nyata-nyata diperlukan, 4) Biaya penyimpanan barang (marhun) dilakukan berdasarkan akad ijarah. Hasil penelitian Mahmudahningtyas dkk (2015) menunjukkan bahwa Rahn emas merupakan produk jasa gadai yang berlandaskan prinsip syariah dimana nasabah tidak dikenakan bunga atas pinjaman yang diperoleh. Dalam transaksi rahn emas, uang atau dana yang dipinjamkan berbentuk pertolongan yang tidak mengharapkan tambahan atas hutang tersebut. Seiring berkembangnya praktik rahn emas di Indonesia, timbul keraguan dari berbagai kalangan atas kesesuaian praktik rahn emas dengan konsep yang ada. 
Berbagai opini menyatakan bahwa praktik rahn emas sama saja dengan gadai emas konvensional. Hasil penelitian ini menunjukkan juga bahwa secara garis besar pegadaian syariah sudah mematuhi aturan dalam transaksi rahn emas namun ada hal-hal yang dianggap kurang sesuai dengan konsep syariah yaitu adanya penggabungan akad rahn dan akad ijarah, penentuan biaya ijarah dan administrasi yang didasarkan pada besarnya pinjaman, serta kurang diperhatikannya status kepemilikan emas. Terlepas dari adanya ketidaksesuaian antara konsep dengan praktik rahn emas di pegadaian syariah, sistem pelelangan yang dilakukan pegadaian syariah sudah sesuai dengan Fatwa DSN-MUI No:25/DSNMUI/III/2002 tentang Rahn. Dalam al Quran dan al Hadits, logam mulia emas dan perak telah disebutkan fungsinya sebagai mata uang atau sebagai harta dan lambang kekayaan yang disimpan. Semua bentuk transaksi baik untuk kegiatan muamalah maupun ibadah seperti zakat dan diyat dilakukan dengan menggunakan dinar dan dirham. Menurut pandangan Islam kepemilikan emas tidaklah dilarang, yang dilarang adalah menumpuk emas untuk mendapatkan keuntungan dari orang lain. Emas boleh dijadikan komoditas untuk menyimpan kekayaan. Kegiatan menyimpan emas untuk kemudian dijadikan komoditas investasi yang mengandung motif spekulasi merupakan praktik yang dilarang dalam agama Islam. Spekulasi merupakan kegiatan yang mengandung gharar atau ketidakjelasan, sehingga praktik ini dilarang.

Ada satu hal yang sangat berbeda dalam memandang uang antara sistem kapitalis dengan sistem Islam. Dalam sistem kapitalis, uang tidak hanya sebagai alat tukar yang sah, melainkan juga sebagai komoditas. Menurut sistem kapitalis, uang juga dapat diperjual belikan yang mendatangkan keuntungan. Ketika uang diperlakukan sebagai komoditas oleh sistem kapitalis maka munculnya pasar uang. Terbentuknya pasar uang ini menghasilkan dinamika dalam sistem konvensional terutama pada sektor moneternya. Pasar uang kemudian berkembang dengan munculnya pasar derivatif, yang merupakan turunan dari pasar uang. Pasar derivatif ini menggunakan instrumen bunga sebagai harga dari produk-produknya. Transaksi di pasar uang dan pasar derivatifnya ini tidak berlandaskan motif transaksi yang riil sepenuhnya, bahkan sebagian besar di antaranya mengandung motif spekulasi (Aghna, 2014:13).

\section{Pengembangan Hipotesis}

Ar-rahn menurut istilah syara' adalah, menahan sesuatu disebabkan adanya hak yang memungkinkan hak itu bisa dipenuhi dari sesuatu tersebut. Maksudnya menjadikan al-Aini (barang, harta yang barangnya berwujud konkrit, kebalikan dari ad-Dain atau utang) yang memiliki nilai menurut pandangan syara' sebagai watsiqah (pengukuhan,jaminan) utang, sekiranya barang itu memungkinkan untuk digunakan membayar seluruh atau sebagian utang yang ada.

Di dalam ranah kognitif dari taksonomi Bloom menunjukkan tingkatantingkatan kemampuan yang dicapai dari yang terendah sampai yang tertinggi. Dapat dikatakan bahwa pemahaman tingkatannya lebih tinggi dari sekedar pengetahuan. Sudijono mendefinisikan pemahaman sebagai kemampuan seseorang untuk mengerti atau memahami sesuatu setelah sesuatu itu diketahui dan diingat. Dengan katalain, memahami adalah mengetahui mengetahui tentang sesuatu dan dapat melihatnya dari berbagai segi. Pemahaman merupakan jenjang kemampuan berpikir yang setingkat lebih tinggi dari ingatan dan hafalan.(Sudijono, 1996:50).

Mahasiswa jurusan akuntansi mempelajari matakuliah Bank dan Lembaga Keuangan. Dalam mata kuliah tersebut terdapat pembelajaran mengenai 
pengadaian syariah yang merupakan bagian dari lembaga keuangan non Bank. Sasaran dan harapan setelah mendapatkan pembelajaran matakuliah tersebut mahasiswa mampu menjelaskan dan dapat menerapkan sistem ekonomi syariah.

$\mathrm{Ha}$ : Variabel matakuliah Bank dan Lembaga Keuangan berpengaruh signifikan terhadap Pemahaman Pegadaian Syariah.

\section{METODE PENELITIAN}

Metode penelitian ini adalah survey dengan pendekatan kuantitatif yaitu pengumpulan dan pengukuran data yang berbentuk angka (Sugiyono, 2017). Populasi yang dimaksud dalam penelitian ini yaitu mahasiawa semester satu diambil 30 orang.Jumlah mahasiswa semester awal atau semester satu jurusan akuntansi Politeknik Negeri Kupang keseluruhan sebanyak 353 orang, dikelompokkan dalam 8 kelas. Sampel dalam penelitian ini adalah individu dari mahasiswa atau kelompok mahasiswa pada semester awal sebanyak 28 orang dari populasi mahasiswa baru diambil secara acak. Teknik pengambilan sampel yang digunakan adalah Simple Random Samplingdengan tingkat kesalahan $5 \%$ dari daftar pengambilan sampel yang dianggap representatif menurut (Sugiyono, 2017). Prinsip pemilihan sampel dalam desain ini adalah setiap elemen dalam populasi mempunyai kesempatan yang sama untuk dipilih (Kuncoro,2003). Data diolah dan dianalisis dengan menggunakan bantuan software SPSS for Windows seri 16.0. Variabel penelitian ini terdiri dari variabel independenvariabel dependen disajikan pada Tabel 1 adalah sebagai berikut:

Tabel 1. Operasionalisasi Variabel

\begin{tabular}{|l|l|}
\hline \multicolumn{1}{|c|}{ Variabel } & \multicolumn{1}{|c|}{$\begin{array}{c}\text { Definisi } \\
\text { operasional }\end{array}$} \\
\hline $\begin{array}{l}\text { Matakuliah } \\
\text { Bank dan } \\
\text { Lembaga }\end{array}$ & $\begin{array}{l}\text { pemahaman } \\
\text { lembaga } \\
\text { Keuangan } \\
\text { (X1) }\end{array}$ \\
\hline
\end{tabular}

\begin{tabular}{|l|l|}
\hline $\begin{array}{l}\text { Lembaga } \\
\text { Keuangan } \\
\text { Non } \\
\text { Bank(X2) }\end{array}$ & $\begin{array}{l}\text { Mampu } \\
\text { menjelaskan } \\
\text { pegadaian syariah }\end{array}$ \\
\hline $\begin{array}{l}\text { Pemahaman } \\
\text { Pegadaian } \\
\text { Syariah(Y) }\end{array}$ & $\begin{array}{l}\text { pemahaman } \\
\text { dalam penelitian } \\
\text { ini didefinisikan } \\
\text { mahasiswa } \\
\text { mampu } \\
\text { menjelaskan } \\
\text { tentang pegadaian } \\
\text { syariah. }\end{array}$ \\
\hline
\end{tabular}

Sumber yang digunakan pada penelitian ini adalah data primer dan data sekunder adalah sebagai berikut:

1. Data primer yaitu data yang diperoleh secara langsung dari subjek penelitian denganmenggunakan alat pengukuran atau pengambilan data langsung pada subjek sebagai sumber informasi yang dicari. Data primer dari penelitian ini berasal dari responden seperti jawaban atas daftar pertanyaan yang peneliti berikan pada 28 orang mahasiswa yang jadi sasaran, berupa data yang berkaitan dengan variabel-variabel yang akan diteliti, yaitu tentang pemahaman pegadaian syariah, matakuliah bank dan lembaga keuangan, dan lembaga keuangan non bank.

2. Data Sekunder adalah data yang diperoleh dengan jaan mengumpulkan dokumen-dokumen serta literatureliteratur yang erat hubungannya dengan penelitian ini. (Sugiyono,2017).

Analisa data merupakan bagian yang amat penting dalam metode ilmiah karena dengan analisa data tersebut dapat diberi arti, yang di pergunakan untuk penyelesaian masalah. Oleh karena itu, tujuan penelitian ini agar tercapai secara optimal, maka data dianalisis secara analisis regresi linier berganda. Analisis Regresi Linear Berganda digunakan untuk mengukur pengaruh antara lebih dari satu variabel independen terhadap variabel 
dependen. Persamaan Regresi sebagai berikut:

$$
Y=a+b 1 X 1+b 2 X 2+\ldots+b n X n
$$

Dimana :

$$
\begin{aligned}
& Y \quad=\text { variabel terikat } \\
& \text { a }=\text { konstanta } \\
& b 1, b 2=\text { koefisien regresi } \\
& X 1, X 2=\text { variabel bebas }
\end{aligned}
$$

\section{HASIL DAN PEMBAHASAN}

Jurusan akuntansi merupakan salah satu jurusan dari lima jurusan yang ada di Politeknik Negeri Kupang yaitu; akuntansi, bisnis, teknik sipil, teknik elektro dan jurusan teknik mesin. Pada tahun 2018 jurusan akuntansi menerima mahasiswa semester satu sebanyak 353 orang terdiri dari diploma 3 (D3) 100 orang dan diploma 4 (D4) 253 orang. Pendidikan pada PNK menyelenggarakan pendidikan proposional vakasi artinya perkuliahan dilaksanakan mengutamakan penerapan pemahaman matakuliah yang diajarkan.

Salah satu mata kuliah unggulan kurikulum local adalah matakuliah Pengantar Bank dan Lembaga Keuangan (PBLK), salah satu topik yang diajarkan adalah Bank Muamalat dengan Bank Syariah dan Ekonomi Syariah yang menyangkut pegadaian syariah. Pegadaian syriah merupakan topik utama dari lembaga keuangan non bank yang diajarkan kepada mahasiswa agar memahami system pegadaian syariah.

Penelitian ini mengambil sampel mahasiswa semester I yang belum mendapatkan matakuliah BLK. Identitas responden dalam penelitian ini meliputi mahasiswa semester I, responden diambil acak sebanyak 28 orang dari populasi semester I mahasiswa akuntansi, deskripsi responden disajikan pada tabel 2 adalah sebagai berikut:

Tabel 2. Deskripsi Responden

\begin{tabular}{|l|l|l|}
\hline SEMESTER & $\begin{array}{l}\text { TAHUN } \\
\text { AJARAN }\end{array}$ & $\begin{array}{l}\text { JUMLAH } \\
\text { (Orang) }\end{array}$ \\
\hline I A D3 & $2018 / 2019$ & 51 \\
\hline
\end{tabular}

\begin{tabular}{|l|l|l|}
\hline I B D3 & $2018 / 2019$ & 59 \\
\hline I A D4 & $2018 / 2019$ & 51 \\
\hline I B D4 & $2018 / 2019$ & 51 \\
\hline IA D4 & $2018 / 2019$ & 51 \\
\hline I B D4 & $2018 / 2019$ & 50 \\
\hline I C D4 & $2018 / 2019$ & 50 \\
\hline I E D4 & $2018 / 2019$ & 50 \\
\hline Jumlah & 353 \\
\hline
\end{tabular}

Sumber : Data Primer di olah, 2018

Uji validitas dengan menggunakan software IBM SPSS statistics 16 diperoleh hasil uji bahwa seluruh item pertanyaan adalah valid karena masing-masing item nilai corrected Item-Total Correlation memiliki nilai lebih besar dari standar minimum $(0,3)$ untuk jelasnya disajikan pada tabel 3, tabel 4 dan tabel 5. Uji validasi dilaksanakan dengan rumus korelasi bivariate person. Item angket dalam uji validasi dikatakan valid bila harga $r$ hitung $>r$ table dan sebaliknya bila harga $r$ hitung $<r$ table maka tidak valid pada nilai signifikan 5\%. $\mathrm{r}$ table adalah $\mathrm{N}$ $=28=0.374$.

Tabel 3. Hasil Uji Validasi Pemahaman Pegadaian Syariah

\begin{tabular}{|c|c|c|c|}
\hline No.Item & $\mathrm{r}$ hitung & $\begin{array}{c}\mathrm{R} \text { table } \\
5 \%(28)\end{array}$ & Keterangan \\
\hline 1 & 0.792 & 0.374 & Valid \\
\hline 2 & 0.435 & 0.374 & Valid \\
\hline 3 & 0.516 & 0.374 & Valid \\
\hline 4 & 0.645 & 0.374 & Valid \\
\hline 5 & 0.745 & 0.374 & Valid \\
\hline 6 & 0.805 & 0.374 & Valid \\
\hline 7 & 0.772 & 0.374 & Valid \\
\hline 8 & 0.665 & 0.374 & Valid \\
\hline 9 & 0.811 & 0.374 & Valid \\
\hline 10 & 0.587 & 0.374 & Valid \\
\hline \multicolumn{2}{|c|}{ Sumber Data Primer di olah 2018 } \\
\hline
\end{tabular}

Sumber : Data Primer di olah, 2018

Tabel 4. Hasil Uji Validasi Modul Pegadaian Syariah

\begin{tabular}{|c|c|c|c|}
\hline \multicolumn{5}{|c|}{ No.Item } & r hitung & $\begin{array}{c}\mathrm{R} \text { table } \\
5 \%(28)\end{array}$ & $\begin{array}{c}\text { Keteranga } \\
\mathrm{n}\end{array}$ \\
\hline 1 & 0,516 & 0.374 & Valid \\
\hline 2 & 0,572 & 0.374 & Valid \\
\hline 3 & 0,743 & 0.374 & Valid \\
\hline 4 & 0,588 & 0.374 & Valid \\
\hline 5 & 0,690 & 0.374 & Valid \\
\hline 6 & 0,554 & 0.374 & Valid \\
\hline 7 & 0,549 & 0.374 & Valid \\
\hline 8 & 0,550 & 0.374 & Valid \\
\hline 9 & 0738 & 0.374 & Valid \\
\hline 10 & 0,634 & 0.374 & Valid \\
\hline \multicolumn{4}{|c}{ Sumber : Data Primer di olah,2018 }
\end{tabular}


Uji realibilitas dilakukan dengan menggunakan rumus alpha. Uji signifikan dilakukan pada taraf $\alpha=0.05$. Hasilnya dapat dikatakan realibilitas bila $\alpha>r$ tabel 0.374. Hasil Uji realibilitas kuesioner Pemahaman Pegadaian Syariah pada Tabel 6 menunjukkan nilai Cronbach's Alpha $(0,864)>0.374$. Artinya bahwa kuesioner Pemahaman Pegadian Syariah dalam penelitian ini adalah reliabel. Demikian pula dengan Tabel 7, nilai Cronbach's Alpha $(0,804)>0.374$. Artinya bahwa kuesioner sikap dalam penelitian ini adalah reliabel.

Tabel 6 . Reliabilitas Variabel Pemahaman Pegadaian Syariah

\begin{tabular}{|l|l|}
\hline \multicolumn{2}{|l|}{ Reliability Statistics } \\
\hline Cronbach's Alpha & Nof Items \\
\hline .864 & 10 \\
Sumber : Data Primer di olah, 2018
\end{tabular}

Tabel 7 : Reliabilitas Variabel Modul Pegadaian Syariah

\begin{tabular}{|l|l|}
\hline \multicolumn{2}{|l|}{ Reliability Statistics } \\
\hline Cronbach's Alpha & N of Items \\
\hline .804 & 10 \\
\hline
\end{tabular}

Sumber : Data Primer di olah, 2018

Tabel 8. Reliabilitas Variabel Perbankan Pegadian Syariah

\begin{tabular}{|l|l|}
\hline \multicolumn{2}{|c|}{ Reliability Statistics } \\
\hline Cronbach's Alpha & N of Items \\
\hline .810 & 10 \\
\hline
\end{tabular}

Sumber : Data Primer di olah, 2018

Dari tabel 8 tersebut nilai Cronbach's Alpha $(0,810)>0.374$. Artinya bahwa kuesioner Perbankan Pegadaian Syariah dalam penelitian ini adalah reliabel. Hasil uji reliabilitas diperoleh nilai koefisien reliabilitas angket $\mathrm{X}-1$ sebesar 0.864 angket X-2 sebesar 0.804 dan Y adalah 0.810. Berdasrkan nilai koefisien reliabilitas tersebut dapat disimpulkan bahwa semua angket dalam penelitian ini reliabilitas atau konsisten sehingga dapat digunakan sebagai instrument.

\section{Pengujian Hipotesis}

Untuk dapat menguji pengaruh tersebut, maka harus dicari persamaan regresinya terlebih dahulu, dari tiga variabel yang dikembangkan untuk menjaring data tentang pengaruh tersebut.
Harga a, b1, b2 dapat menggunakan persamaan berikut :

$$
\sum Y=a n+b 1 \sum X 1+b 2 \sum X 2
$$

$\sum X 1 Y=a \sum X 1+b 1 \sum X^{2} 1+b 2 \sum X 1 X 2$

$\Sigma X 2 Y=a \sum X 2+b 1 \sum X 1 X 2+b 2 \sum X^{2}$

Tabel 9. Model Summary

\begin{tabular}{|l|l|l|l|l|}
\hline \multicolumn{5}{|l|}{ Model Summary } \\
\hline Model & $\mathrm{R}$ & R Square & $\begin{array}{l}\text { Adjusted R } \\
\text { Square }\end{array}$ & $\begin{array}{l}\text { Std. Error of } \\
\text { the Estimate }\end{array}$ \\
\hline 1 & $.566^{\mathrm{a}}$ & .321 & .266 & 5.371 \\
\hline \multicolumn{5}{|l}{ a. Predictors: (Constant), $\mathrm{x} 2, \mathrm{x} 1$} \\
\hline
\end{tabular}

Sumber : Data Primer di olah, 2018

Tabel 9 ini memberi informasi seberapa baik model analisis secara keseluruhan, yaitu bagaimana variabel bebas mampu memprediksikan satu variabel terikat, dengan rincian sebagai berikut ini. Nilai $\mathrm{R}$ dapat dicari dengan menggunakan rumus :

$\mathrm{R}=\frac{\mathrm{b} 1 \sum \mathrm{X} 1 \mathrm{Y}+\mathrm{b} 2 \sum \mathrm{X} 2 \mathrm{Y}}{\sum_{\mathrm{Y}} 2}$

Kolom R 0,566. Menunjukkan bahwa variabel-variabel bebas memprediksikan hasil (multiple correlation coefficient). Kisaran nilai $\mathrm{R}$ adalah 0 hingga 1 . Semakin nilai $R$ mendekati angka 1, maka semakin kuat variabel-variabel bebas memprediksikan variabel terikat. Namun, ketepatan nilai $\mathrm{R}$ ini lebih disempurnakan oleh kolom Adjusted $R$ Square yang merupakan koreksi atas nilai R. Kolom Adjusted $R$ Square sebesar 0,266. Menunjukkan bahwa nilai Adjusted R Square kecil masih dalam kisaran standar. Kisaran nilai Adjusted $R$ Square adalah 0 hingga 1. Nilai Koefisien Determinasi $\left(\mathrm{R}^{2}\right)$ didapat sebesar 0,321

\section{F hitung}

F hitung dapat dihitung dengan menggunakan rumus :

F Hitung $=\frac{R^{2}(N-k-1)}{k\left(1-R^{2}\right)}$ 
Berdasarkan uji statistik dengan menggunakan software IMB SPSS statistcdseri 24.0 diperoleh $F$ hitung sebesar 5.899 untuk F tabel pada df 2 dan $\mathrm{dk} 25=3.30$.Dengan menggunakan Tingkat signifikansi menggunakan $\alpha=5 \%$ (signifikansi 5\% atau 0,05, hasil diperoleh untuk Ho ditolak, Ha diterima. Jadi, dapat disimpulkan bahwa variabel matakuliah Bank dan Lembaga Keuangan berpengaruh signifikan terhadap pemahaman Pegadaian Syariah. Hipotesis tersebut merupakan dari hasil penelitian mahasiswa Politeknik Negeri Kupang jurusan akuntansi angkatan 2018 yang telah mendapatkan matakuliah perbankan syariah.

\begin{tabular}{|c|c|c|c|c|c|c|}
\hline \multicolumn{7}{|c|}{ Tabel 10.Uji F ANOVA } \\
\hline \multicolumn{2}{|c|}{ Model } & $\begin{array}{l}\text { Sum of } \\
\text { Squares }\end{array}$ & df & $\begin{array}{l}\text { Mean } \\
\text { Square }\end{array}$ & $\mathrm{F}$ & Sig. \\
\hline \multirow[t]{3}{*}{1} & $\begin{array}{l}\text { Regressio } \\
n\end{array}$ & 340.418 & 2 & 170.209 & 5.899 & $.008^{\mathrm{b}}$ \\
\hline & Residual & 721.297 & 25 & 28.852 & & \\
\hline & Total & 1061.714 & 27 & & & \\
\hline \multicolumn{7}{|c|}{ a. Dependent Variable: $y$} \\
\hline \multicolumn{7}{|c|}{ b. Predictors: (Constant), x2, x1 } \\
\hline
\end{tabular}

Sumber : Data Primer di olah, 2018

Penelitian ini dilakukan untuk mengetahui pemahaman mahasiswa akuntansitentang pegadaian syariah. Berdasarkan 28 responden yang digunakan sebagai sumber data penelitian. Pengujian instrumen menunjukkan bahwa instrument tersebut dapat digunkan dalam penelitian ini berdasarkan uji Validitas dan uji Realibilitas seluruh item pertanyaan adalah valid karena masing-masing item nilai corrected Item-Total Correlation memiliki nilai lebih besar dari standar minimum $(0,3)$, nilai Cronbach's Alpha $(0,810)$ $>0.374$. Artinya bahwa semua kuesioner dalam penelitian ini adalah reliabel.

Nilai koefisien korelasi berganda menunjukkan angka $\mathrm{R}$ 0,321 menjatakan bahwa nilai tersebut kisaran nilai $\mathrm{R}$ adalah 0 hingga 1 termasuk katagori rendah, hal tersebut bisa disebabkan oleh sampel yang dituju masih memerlukan pembinaan tentang perbankan syariah. Sedangkan nilai Adjusted $R$ Square kecil masih dalam kisaran standar namun buruk ketepatannya pada kisaran nilai Adjusted $R$ Square adalah 0 hingga 1 masih dibawah angka $<$ 0 .321. Dari hasil output analisis regresi dapat diketahui nilai $\mathrm{F}$ sebesar 5.899 , tingkat signifikansi menggunakan $\alpha=5 \%$ (signifikansi $5 \%$ atau 0,05 ), hasil uji hipotesis menghasilkan bahwa $\mathrm{F}$ hitung $\leq$ $\mathrm{F}$ tabel $=$ Ho ditolak, artinya variabel matakuliah Bank dan Lembaga Keuangan berpengaruh signifikan terhadap pemahaman Pegadaian Syariah, hal ini disebabkan kemungkinan mareka tidak asing lagi dengan bank syariah bagi mahasiswa jurusan akuntansi politeknik negeri kupang.

\section{KESIMPULAN}

Hasil penelitian ini menunjukkan bahwa mahasiswa jurusan akuntansi semester satu cenderung memahami tentang pegadaian syariah, karena sebagian besar mahasiswa telah mendapatkan topic matakuliah tersebut. Beberapa sikap, motivasi dan minat mahasiswa berwirausaha dipengaruhi ketidak pahaman menjalankan usaha. Hasil pengujian hipotesis menunjukkan bahwa Uji hipotesis menghasilkan bahwa $\mathrm{F}$ hitung $\leq \mathrm{F}$ tabel $=$ Ho ditolak, artinya variabel matakuliah Bank dan Lembaga Keuangan berpengaruh signifikan terhadap pemahaman Pegadaian Syariah. Hipotesis tersebut merupakan dari hasil penelitian mahasiswa Politeknik Negeri Kupang jurusan akuntansi angkatan 2018 yang telah mendapatkan matakuliah perbankan syariah. Penelitian ini perlu dikembangkan sampai ada pelaksaan di lapangan peneraapan perekonomian syariah

Disarankan untuk penelitian lebih lanjut dapat dilaksanakan untuk diuji kembali variabel penerapan perekonomian syariah. Penelitian ini lebih bermanfaat bila institusi Politeknik Negeri Kupang dapat menerapakan pada semua jurusan. Dari hasil penelitian ini, sebagian besar mahasiswa telah memahami pegadaian syariah. 


\section{UCAPAN TERIMA KASIH}

Penulis mengucapkan terima kasih kepada Direktur Politeknik Negeri Kupang, Kepala P3M Politeknik Negeri Kupang, Ketua Jurusan Akuntansi, Teman sejawat dan mahasiswa yang terlibat atas penelitian ini. Penelitian Terapan ini dibiayai dana DIPA Politeknik Negeri Kupang Tahun Anggaran 2018.

\section{DAFTAR PUSTAKA}

Anas Sudijono.(1996) Pengantar Evaluasi Pendidikan. Raja Grafindo Persada. Jakarta.

$$
\begin{aligned}
& \text { Al-Hafizh, M (2013), } \\
& \text { PengertianPemahaman Dalam } \\
& \text { Pembelajaran. } \\
& \text { http://www.referensimakalah.com } \\
& \text {.Diakses 12/5/2018. }
\end{aligned}
$$

Aghna. (2014). Motif Uang. https://www.academia.edu diakses 13/5/2018.

Raikhan (2017). Efisiensi Pegadaian Syariah dan Prospek Pertumbuhan Aset di Indonesia. al-Uqud: Journal of Islamic Economics Volume 1 Nomor 1, Januari 2017E-ISSN 2548-3544, P-ISSN 2549-0850 Halaman 5982.

Nasution,R.S (2016). Sistem Operasional Pegadaian Syariah Berdasarkan Surah Al-Baqarah 283 pada PT. Pegadaian (Persero) Cabang Syariah Gunung Sari Balikpapan. Al-Tijary. Jurnal Ekonomi dan Bisnis Islam 2016, Vol. 1, No. 2, Hal. 93-119.

Putra.P (2015). Analisis Tingkat Pemahaman Mahasiswa terhadap Pernyataan Standar Akuntansi Keuangan Syariah Psak-
Syariah.JRAK. Vol.6 No.1 Februari 2015 hal. 38-50.

Gardner, H. 1999. Gardner, The dicipline mind: What all students should understand. New York: Simon \& Schuster Inc.

Purwanto, N. 1997. Prinsip-Prinsip dan Teknik Evaluasi Pengajaran cet. ke-8. h. 44. Bandung, Jawa Barat, Indonesia: PT. Remaja Rosdakarya.

Mahmudahningtyas.A, Manzilati,(2015). analisis kesyariahan transaksi rahn emas (studi pada pegadaian syariah cabang landungsari malang). FE. Brawijaya Malang

Winkel, W. S. 1996. Psikologi Pengajaran (Vol. cetakan ke 4 ). Jakarta, Indonesia: PT. Gramed 